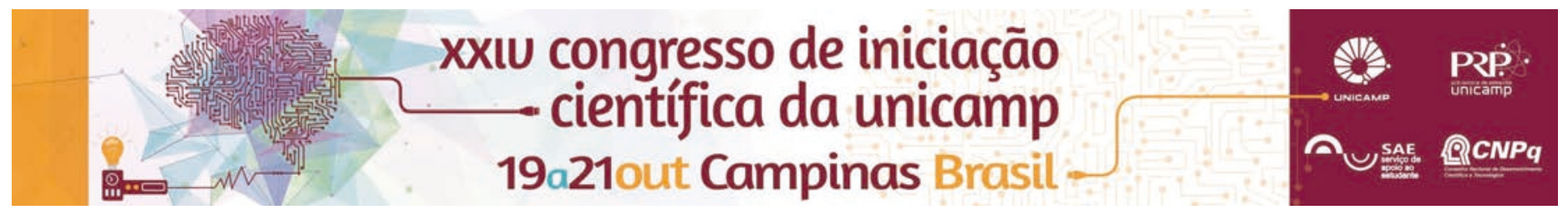

\title{
Análise de Ferramentas de Captura de Baixo Custo para levantamento de edificações existentes visando a construção do modelo As-built BIM.
}

\author{
Pablo B. A. Cunha*, Profa. Dra. Eloisa Dezen-Kempter.
}

\section{Resumo}

O objetivo deste projeto de iniciação científica foi analisar ferramentas de baixo custo para levantamento da condição as-is de edificações existentes, visando gerar a documentação as-built BIM do edifício. Foram avaliados softwares de fotogrametria e para tratamento de nuvens de pontos, do tipo open source e proprietários, e equipamentos de varredura como o laser scanner 3D, sensores de mão, e câmeras fotogáficas. A pesquisa foi aplicada a um estudo de caso, o Edifício Prada, prédio industrial construído em 1938 em alvenaria e concreto para as instalações da Fábrica de Chapéus Prada, que atualmente abriga o Paço Municipal de Limeira. Nas varreduras utilizou-se metodologia hibrida para acaptura de dados geoespaciais, que posteriormente foram processados e analisados em diferentes programas priorizando aspectos como custo, precisão e facilidade de pós-processamento das informações.

\section{Palavras-chave:}

Fotogrametria, escaneamento tridimensional, modelo as-built.

\section{Introdução}

Atualmente uma maior atenção tem sido voltada tanto para práticas mais sustentáveis na Construção Civil quanto para a eficiência na operação e manutenção de edificações existentes, pois estas têm grande impacto no meio ambiente, economia e produtividade (WOO et al. 2010). A modelagem BIM proporciona vantagens significativas na criação de novos projetos e adaptação de edifícios existentes que priorizam qualidade, sustentabilidade e eficiência de operação, pois esta tecnologia agrega num modelo virtual tridimensional informações das diferentes disciplinas envolvidas na criação do projeto (SANTOS; BARISON, 2011). Nos casos dos edifícios existentes é necessário um levantamento da condição as-is para a geração da documentação as-built, este processo é feito através de varreduras como fotogrametria ou escaneamento tridimensional.

\section{Resultados e Discussão}

Os recentes avanços das tecnologias de varredura, empregadas no levantamento da condição as-is do estoque de edificações existentes, contribuem para a precisão dos dados levantados e facilitam o trabalho de campo. Contudo estas tecnologias ainda possuem custos elevados. Esta pesquisa buscou formas mais acessíveis (econômica e tecnologicdamente) para se obter e trabalhar os dados geométricos das edificações existentes, ainda sim priorizando a precisão do resultado final.

A captura dos dados geoespaciais do estudo de caso foi feita de forma hibrida através de escaneamento $3 D$ (Figura 1) a laser e imagens aéreas obtidas com VANT (Veículo Aéreo não tripulado). Com os dados obtidos nas varreduras gerou-se diversas nuvens de pontos em diferentes softwares e comparou-se os resultados.

Para obter uma melhor eficiência de cada software foram revisadas suas respectivas orientações de uso disponibilizadas, pelos fabricantes em manuais e vídeos explicativos, ou por outros usuários que já registraram alguma experiência em trabalhos anteriores. A forma de processamento dos dados variou de acordo com o software usado, mas em todos os casos foi bem intuitiva e não sendo necessário nenhum conhecimento técnico específico, sendo que alguns deles processavam os dados em nuvem, não sendo necessário equipamentos sofisticados e de alto desempenho.

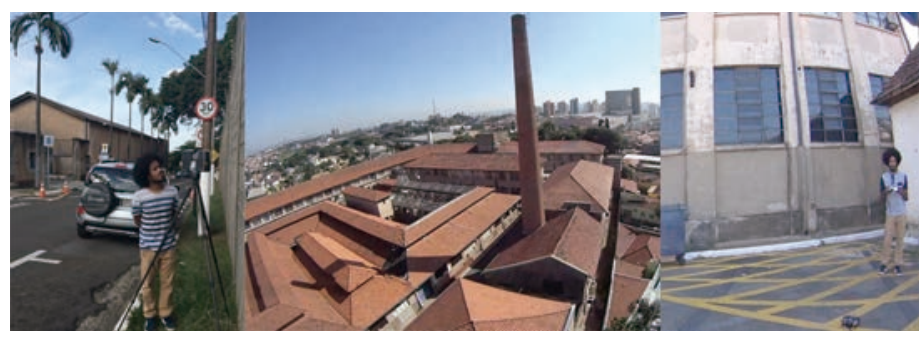

Figura 1. Aluno operando o laser scanner 3D e o VANT, imagem aérea do Edifício Prada.

\section{Conclusões}

A documentação as-built BIM de edificações existentes, que auxilia na tomada de decisões de manutenção e operação da obra assim como na preservação de Patrimônio Histórico, tem como requisito o levantamento preciso da condição as-is, que é gerado a partir de dados geoespaciais da construção. Essas medições podem ser obtidas por diferentes métodos e com o uso de variadas tecnologias, apesar dos custos ainda elevados do escaneamento a laser 3D a precisão dos dados capturados é milimétrica.

Este projeto possibilitou a desenvolver uma metodologia mais acessível para a captura dos dados necessários para gerar a documentação BIM, visando precisão e rapidez nos levantamentos da condição as-is de préexistências

\section{Agradecimentos}

Agradeço à Profa. Dra. Eloisa Dezen-Kempter, à Unicamp, ao SAE e ao CNPq pela oportunidade e aos meus amigos e familiares pelo apoio.

\footnotetext{
WOO, J., WILSMANN, J., KANG, D. (2010) Use of As-Built Building Information Modeling. Construction Research Congress 2010, pp. 538-548.

2 SANTOS, E. T.; BARISON, M. B. (2011) "BIM e as Universidades". Revista Construção Mercado, Editora Pini Ltda., São Paulo, v.115, fev. 2011.
} 